Weiland, A., Blankenstein, A.H., Willems, M.H.A., Saase, J.L.C.M. van, Molen, H.T. van der, Dulmen, A.M. van, Arends, L.R. Post-graduate education for medical specialists focused on patients with medically unexplained physical symptoms: development of a communicationskills training programme. Patient Education and Counseling: 2013, 92(3), 355-360

\begin{tabular}{|l|l|}
$\begin{array}{l}\text { Postprint } \\
\text { Version }\end{array}$ & 1.0 \\
\hline Journal website & http://www.pec-journal.com/article/S0738-3991(13)00272-3/abstract \\
\hline Pubmed link & http://www.ncbi.nlm.nih.gov/pubmed/23906652 \\
\hline DOI & $10.1016 /$ j.pec.2013.06.027
\end{tabular}

This is a NIVEL certified Post Print, more info at http://www.nivel.eu

\title{
Post-graduate education for medical specialists focused on patients with medically unexplained physical symptoms; development of a communication skills training programme
}

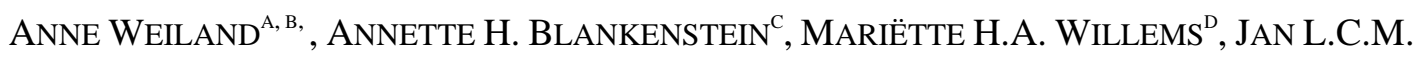 \\ VAN SAASE ${ }^{\mathrm{E}}$, HeNK T. VAN DER MOLEN ${ }^{\mathrm{F}}$, ALEXANDRA M. VAN DULMEN ${ }^{\mathrm{G}, \mathrm{H}, \mathrm{I}}$, LIDIA R. \\ ARENDS $^{\mathrm{J}, \mathrm{K}}$ \\ ${ }^{a}$ Department of Internal Medicine, Erasmus MC, University Medical Center, Rotterdam, The \\ Netherlands \\ ${ }^{b}$ Faculty of Social Sciences, Institute of Psychology, Erasmus University Rotterdam, \\ Rotterdam, The Netherlands \\ ${ }^{c}$ Department of General Practice and Elderly Care Medicine, VU University Medical Center, \\ Amsterdam, The Netherlands \\ ${ }^{\mathrm{d}}$ Department of Neurology, Erasmus MC, University Medical Center, Rotterdam, The \\ Netherlands \\ ${ }^{\mathrm{e}}$ Department of Internal Medicine, Erasmus MC, University Medical Center, Rotterdam, The \\ Netherlands \\ ${ }^{f}$ Faculty of Social Sciences, Institute of Psychology, Erasmus University Rotterdam, \\ Rotterdam, The Netherlands \\ ${ }^{9}$ NIVEL (Netherlands Institute for Health Services Research), Utrecht, The Netherlands \\ ${ }^{\mathrm{h}}$ Department of Primary and Community Care, Radboud University Nijmegen Medical \\ Centre, The Netherlands \\ i Department of Health Science, Buskerud University College, Drammen, Norway \\ ${ }^{j}$ Faculty of Social Sciences, Institute of Psychology and Institute of Pedagogy, Erasmus \\ University Rotterdam, Rotterdam, The Netherlands \\ k Department of Biostatistics, Erasmus MC, University Medical Center, Rotterdam, The \\ Netherlands
}

\begin{abstract}
Objective: Stepwise description of the development of a post-graduate communication skills training programme for medical specialists focused on patients with medically unexplained physical symptoms (MUPS) to improve specialist interaction with MUPS patients.

Methods: Using the 'intervention mapping approach' we accomplished a needs assessment (literature study and pilot) to formulate intervention objectives and identify methods and techniques for a MUPS-focused communication skills training programme for medical specialists.
\end{abstract}


Weiland, A., Blankenstein, A.H., Willems, M.H.A., Saase, J.L.C.M. van, Molen, H.T. van der, Dulmen, A.M. van, Arends, L.R. Post-graduate education for medical specialists focused on patients with medically unexplained physical symptoms: development of a communication skills training programme. Patient Education and Counseling: 2013, 92(3), 355-360

Results: A 14-h training programme which consists of experiential learning, role-play and feedback. Using skills from Cognitive Behavioural Therapy, medical specialists are stimulated to explore interrelating factors that reinforce symptoms, to reassure patients effectively and to provide plausible and understandable explanations for MUPS. Dealing with complex referrals and informing GPs properly are also practiced.

Conclusion: By applying the 'intervention mapping approach' we were able to create a feasible and promising intervention to improve specialist interaction with MUPS patients. Intervention effects are currently being assessed in a randomized controlled trial.

Practice implications: If the RCT demonstrates sufficient effectiveness and efficiency of the MUPS focused communication skills training programme for medical specialists the intervention could be embedded in post-graduate education of medical specialists and residents.

\section{INTRODUCTION}

Experiencing physical symptoms is quite normal. In community population surveys $85-95 \%$ of respondents report at least one symptom during the preceding week ${ }^{[1]}$. In general practice $30-50 \%$ of the presented physical symptoms remain medically unexplained. In hospital practice this figure is even higher: $40-60 \%{ }^{[2]}$. Although most of these symptoms disappear within several months, $20-30 \%$ of medically unexplained physical symptoms (MUPS) still persist for more than one year ${ }^{[3]}$. Patients with persistent MUPS often have reduced subjective health with impaired physical, mental or social functioning, increased prevalence of co-morbid depressive or anxiety disorders and increased sick-leave ${ }^{[4]}$. MUPS are more prevalent among women and associated with older age, lower education, employment disability and unemployment ${ }^{[5]}$.

When physicians (such as GPs, neurologists, gynaecologists, gastroenterologists, rheumatologists) have no medical explanation for persisting physical symptoms many patients feel that they are not being taken seriously, whereas doctors often feel unable to come to an agreement with their patients on problem definition ${ }^{[6]}$. Patients are easily offended by incongruent messages about supposed non-somatic origins of the symptoms, and experience lack of empathy and acceptance for the physical symptoms ${ }^{[7]}$. These experiences hamper adequate doctor-patient interactions, a proper exploration of problems and management for persistent MUPS ${ }^{[8]}$. Several studies of patients' perspectives on consultations point to the importance of patients seeking legitimacy for their problems ${ }^{[9]}$ and ${ }^{[10]}$. Qualitative analyses have shown how doctors' explanations can create common ground that allows patients and doctors to address both psychosocial and physical aspects of the symptoms and to avoid unnecessary somatic interventions ${ }^{[11]},{ }^{[12]}$ and ${ }^{[13]}$. Teaching about symptom explanation in medical education is, however, limited and explanatory skills are underestimated in the curriculum ${ }^{[6]}$. MUPS-focused 
Weiland, A., Blankenstein, A.H., Willems, M.H.A., Saase, J.L.C.M. van, Molen, H.T. van der, Dulmen, A.M. van, Arends, L.R. Post-graduate education for medical specialists focused on patients with medically unexplained physical symptoms: development of a communicationskills training programme. Patient Education and Counseling: 2013, 92(3), 355-360

communication skills training is available in Dutch post-graduate education for GPs and GP-trainees ${ }^{[14]}$, but not for medical specialists and residents. Comorbidity, lack of clear guidelines and limited knowledge about MUPS among non-psychiatric specialists ${ }^{[15]}$, ${ }^{[16]}$ and ${ }^{[17]}$ often cause unnecessary medical interventions and unintentionally reinforce somatization ${ }^{[18]}$. Normal test results of additional specialist investigations do not naturally reassure MUPS patients ${ }^{[19]}$ and ${ }^{[20]}$. Medical specialists sometimes choose to leave patient-centred explanations about MUPS to the GP, and feel incompetent or unsatisfied about their consultations with MUPS patients ${ }^{[21]}$. To improve the quality of the consultation the medical specialist needs effective tools for determining the optimal strategy for patients with MUPS.

Development of post-graduate education programmes for medical specialists focused on MUPS patients might improve specialist MUPS care.

The purpose of this paper is to describe the development of an evidence-based training programme for medical specialists focused on patients with MUPS, which provides physicians with optimal communication tools for effective specialist MUPS care.

\section{METHODS}

We used the intervention mapping framework to systematically apply theories, empirical evidence and practice perspectives in the development of a MUPS-focused communication skills training programme for medical specialists ${ }^{[22]}$. Intervention mapping (IM) comprises six steps, which are shown in Fig. 1. In the first step we accomplished a needs assessment, including literature study and a pilot training programme for neurologists (staff and residents). The second step contained the description of the intervention objectives. In the third step we selected educational methods and techniques to match the intervention objectives. Then, in the fourth step we elaborated the intervention content, which is the MUPS-focused communication skills training programme for medical specialists. In the fifth step we formulated the implementation plan. In the final step we wrote a research protocol for a randomized controlled trial to evaluate the effectiveness and efficiency of the intervention. This section describes how the steps were operationalized.

\section{[FIGURE 1]}

\subsection{Step 1. Needs assessment}

We used results from our literature study on determinants of non-psychiatric specialist communication focused on patients with MUPS. The publications were retrieved from PubMed, PsychInfo and Embase till April 2011. Medically Unexplained Physical Symptoms was searched in four different ways. The word ‘ unexplained' and its synonym was combined with 'subjective symptoms' and its synonyms, with behaviours often occurring in MUPS patients and for general complaints (such as headache) combined with factors that make it unexplained (such as chronic). This search for MUPS was combined with a search for non-psychiatric specialist or secondary care and their synonyms and with a search for interaction as a combination of synonyms for the word professional near the word patient. 
Weiland, A., Blankenstein, A.H., Willems, M.H.A., Saase, J.L.C.M. van, Molen, H.T. van der, Dulmen, A.M. van, Arends, L.R. Post-graduate education for medical specialists focused on patients with medically unexplained physical symptoms: development of a communication skills training programme. Patient Education and Counseling: 2013, 92(3), 355-360

A pilot training programme, based on the existing Dutch GP training programme for MUPS patients ${ }^{[14]}$, was performed for the Department of Neurology of the Erasmus University Medical Centre Rotterdam in 2007/2008. We measured attendance, and self-reported evaluation of the 22 participating physicians about the content and setup of the training programme, by a questionnaire.

\subsection{Step 2. Intervention objectives}

The result of the pilot training programme was discussed by the Central Education Committee of the Erasmus University Medical Centre Rotterdam as well as six trainers from the MUPS-focused communication skills training programme for GPs. To achieve the overall aim of the intervention (to improve specialist care for MUPS patients) specific objectives for change of the specialists' behaviours were formulated, based on literature and pilot.

\subsection{Step 3. Methods and techniques to change the doctor's behaviour}

Literature about educational methods and communication strategies for medical specialists in consultations with MUPS patients were studied to identify appropriate methods and techniques in accordance with the intervention objectives.

\subsection{Step 4. Intervention content}

The intervention objectives and selected methods and techniques were written down in a training programme. A manual for participants and a separate manual for trainers were developed. Three draft versions of this programme were discussed by the chairman of the Central Education Committee, two educational advisors of the Erasmus Medical University Centre Rotterdam and six trainers, already selected for the implementation of this training programme in six different hospitals.

\subsection{Step 5. Implementation}

Implementation of the intervention was realized in cooperation with six Dutch hospitals as part of a research project on the effectiveness and efficiency of a MUPSfocused communication skills training programme for medical specialists and residents. A total of 120 doctors was recruited and trained in groups of twelve persons by two senior-trainers; the trainings group could be extended to a maximum of 15 persons, in which case a third assistant-trainer was added.

\subsection{Step 6. Evaluation}

To measure the effects of the intervention on doctor and patient outcomes we drafted a research proposal for a randomized controlled trial.

\section{RESULTS}

\subsection{Needs assessment}

We performed a literature review to determine which communication skills are known to have a positive influence on outcome and use of health care in MUPS patients ${ }^{[23]}$. The results confirmed the importance of communication in specialist 
Weiland, A., Blankenstein, A.H., Willems, M.H.A., Saase, J.L.C.M. van, Molen, H.T. van der, Dulmen, A.M. van, Arends, L.R. Post-graduate education for medical specialists focused on patients with medically unexplained physical symptoms: development of a communicaticeskills training programme. Patient Education and Counseling: 2013, 92(3), 355-360

care for MUPS patients. Perceiving patients' expectations correctly enables

specialists to influence patients' cognitions and attributions, to reduce patients' anxiety and to improve patients' satisfaction ${ }^{[24]}$. Providing patients with information about normal test results prior to investigation helps patients to feel more reassured after the consultation (12). Patients report less symptoms and health anxiety when symptoms are explained properly for example by using a communication protocol and a information leaflet in which the MUPS are explained ${ }^{[25]}$. Positive doctorpatient interaction and positive feedback from the doctor contribute to reduced use of health care and better coping with the symptoms ${ }^{[21]},{ }^{[26]},{ }^{[27]},{ }^{[28]},{ }^{[29]}$ and [30]. These elements were integrated in the training programme.

A 14-h pilot training programme was conducted in two groups for a total of 22 neurologists (staff and residents), directed by two senior trainers. The training model was based on experiential learning and particularly focused on the improvement of exploration and information skills of medical specialists ${ }^{[31]}$. Table 1 shows the results of the pilot evaluation. Nineteen of the 22 enrolled physicians attended the course completely and completed the questionnaire.

\section{[TABLE 1]}

Participants evaluated the specific skills for symptom exploration, informing patients about the nature of medically unexplained symptoms and effectively reassuring patients as very useful. Skills that required more than one consultation, like symptom diaries and reattribution, or were perceived to be the domain of other health care professionals (such as psychologists or GPs), were evaluated as less useful in specialist practice and removed from the training programme.

\subsection{Intervention objectives}

Based on the literature the achievement of knowledge about the epidemiology, aetiology and treatment of patients with MUPS and somatoform disorders was selected to be the first objective in the training programme ${ }^{[18]}$. The acquisition of skills in explanation such as informing patients about the nature of MUPS and effectively reassuring patients with MUPS was chosen as the second major objective ${ }^{[6]}$. Answering patients main concerns, performing attention to the somatic symptoms, sharing conclusions based on findings and using clinical experience are key elements of effective reassuring ${ }^{[32]}$. Adequate report to the GP who had referred the patient, containing the explanation and advice given to the patient about MUPS was defined as the third main objective of the course ${ }^{[33]}$.

\subsection{Methods and techniques to change doctors' behaviours}

The Structured Learning Technique (SLT) and Cumulative Micro Training (CMT) were used in the design of the communication skills training programme for medical specialists ${ }^{[34]}$ and ${ }^{[35]}$. Structured learning focuses on shaping conditions that facilitate acquisition of skills and transfer of these skills to daily practice. Cumulative Micro Training (CMT) is a method in which theoretical instruction, modelling, 
Weiland, A., Blankenstein, A.H., Willems, M.H.A., Saase, J.L.C.M. van, Molen, H.T. van der, Dulmen, A.M. van, Arends, L.R. Post-graduate education for medical specialists focused on patients with medically unexplained physical symptoms: development of a communicaticeskills training programme. Patient Education and Counseling: 2013, 92(3), 355-360

\section{(1)}

practicing by role plays, feedback, social and self reinforcement and identifying personal learning points improve professionals' competence in communication skills. Techniques from Cognitive Behaviour Therapy were adjusted to improve the exploration of symptoms and explanation of MUPS by medical specialists ${ }^{[36]}$. In the exploration phase of the consultation for example doctors were taught explicitly to use the CBT-scheme in their search for connections between patients' cognitions, emotions, behaviour that might reinforce the symptoms.

\subsection{Intervention content (duration per session $4 \mathrm{~h}$, the last session $2 \mathrm{~h}$ )}

\subsubsection{First session}

As a result of the previous steps we started the training programme with an exercise, which enabled the medical specialists to gain awareness of their personal thoughts, feelings and behaviour towards patients with MUPS. They were invited to write associations about a MUPS patient in key-words and categorize these key-words under the headings Cognitions, Emotions and Behaviour. Plenary discussion and a search for interrelating factors that reinforce symptoms led to explanation of the theoretical principles of Cognitive Behaviour Therapy. Practical exercises on symptom exploration on Somatic, Cognitive, Emotional, Behavioural and Social aspects of patient's symptoms (SCEBS symptom exploration) was the second exercise. The skills were demonstrated by a physician and a simulated patient and shown on a DVD. Summarizing the patient's worries and informing patients about interrelating factors that reinforce their symptoms was the third exercise. This session ended with a practical exercise in which doctors were taught to present their analysis of the interrelating factors that reinforce symptoms in a drawn vicious circle or downward spiral. Homework consisted of applying the skills in their consultations and reading the manual.

\subsubsection{Second Session}

The session started with sharing the results of practicing the skills of the first session during the homework exercise. Effectively reassuring MUPS patients was practiced. Skills necessary in the management of the expectations of MUPS patients were demonstrated by a DVD and practiced. Discussions about complex referrals and cooperation with the referring physician were facilitated. In exercises skills such as " how to inform a patient prior to testing' and 'informing GPs properly' were practiced. Homework consisted again of using the skills in real consultations and reading the next section of the manual.

\subsubsection{Third session}

This session started with the exchange of reports to the GP, written by the specialist about a MUPS patient in the interval between sessions. Discussion about the quality of the letters and feedback by peers and trainers aimed to improve the specialist care and cooperation with the referring GPs. Information and instruction about referring patients to mental health care was provided. In dyad the medical specialists presented cases in which they practiced the new skills from previous sessions and discussed 
Weiland, A., Blankenstein, A.H., Willems, M.H.A., Saase, J.L.C.M. van, Molen, H.T. van der, Dulmen, A.M. van, Arends, L.R. Post-graduate education for medical specialists focused on patients with medically unexplained physical symptoms: development of a communicationskills training programme. Patient Education and Counseling: 2013, 92(3), 355-360

failures and successes. Homework consisted of watching their own videotaped consultations with MUPS patients prior to the training.

\subsubsection{Fourth session}

The fourth session started with a self-efficacy questionnaire about the required skills for dealing effectively with MUPS ${ }^{[37]}$. The skills on which the doctors evaluated themselves as being less competent were practiced once more. A goal setting exercise at the end of the training reinforced the implementation of the MUPSfocused consultation skills. Participants formulated a personal, specific goal to strengthen their skills during the next weeks in their consultations with MUPS patients. This specific goal was sent back to them on a post-card after a month as a reminder. An evaluation form about the set-up and the content of the training was the closing activity of the training programme. Table 2 presents a summary of the MUPSfocused doctor-patient communications skills and ${ }^{\text {Table } 3}$ shows an overview of the content of the original GP MUPS-focused training programme and the final specialist MUPS-focused training programme.

\section{[TABLE 2] [TABLE 3]}

\subsection{Implementation}

In August 2011 the training was completed. An introduction leaflet was developed and a website with information about the course was designed. Medical specialists and residents of six Dutch hospitals could register online as participants of the randomized controlled trial, with courses scheduled in 2012 and 2013.

\subsection{Evaluation}

We designed a research protocol for a randomized controlled trial to measure the effectiveness and efficiency of this communication skills training programme for medical specialists focused on MUPS patients. The objective is to improve medical specialist care for MUPS patients.

\section{DISCUSSION AND CONCLUSION}

\subsection{Discussion}

\subsubsection{Main findings}

The purpose of our paper was the stepwise description of the development of an evidence-based training programme for medical specialists focused on patients with MUPS in order to provide physicians with optimal communication tools for effective specialist MUPS care.

Medical specialists reported to profit from the skills in exploring, informing and reassuring patients with MUPS and experienced more satisfaction in their medical encounters with MUPS patients. Specialists and residents experienced the consultation skills training programme focused on MUPS patients as useful for their clinical practice. 
Weiland, A., Blankenstein, A.H., Willems, M.H.A., Saase, J.L.C.M. van, Molen, H.T. van der, Dulmen, A.M. van, Arends, L.R. Post-graduate education for medical specialists focused on patients with medically unexplained physical symptoms: development of a communicationskills training programme. Patient Education and Counseling: 2013, 92(3), 355-360

\subsubsection{Comparison with literature}

A recent overview of systematic reviews on effective training strategies for teaching communication skills to physicians by Berkhof et al. ${ }^{[38]}$ showed that effective training programmes include active, practice-oriented strategies. They identified twelve systematic reviews on communication skills training programmes for physicians. Training programmes were effective if they lasted for at least one day, were learner-centred, and focused on practising skills. The best training strategies within the programmes included role-play, feedback, and small group discussions. In a crossover randomized controlled trial Fossli Jensen et al. ${ }^{[39]}$ evaluated the effectiveness of a short course in clinical communication for 51 hospital doctors. They demonstrated that a 20-h course based on the original American Four Habits model could be generalized across medical and national cultures, resulting in a significant improvement in communication skills as measured by the Four Habits Coding Scheme among hospital employed doctors across specialties. These Four Habits were: invest in the beginning, elicit the patient's perspective, demonstrate empathy and invest in the end. Both studies were recently performed and confirmed the chosen set up for our training course for hospital doctors.

\subsubsection{Strengths and limitations}

The feasibility of the training programme was measured by the attendance of the doctors to the course, which was $86 \%$. Second, the training programme had a very strong connection with the daily, clinical practice. Based on the steps of the Intervention Mapping the content of the final training has gained more focus and efficiency.

The evaluation of the pilot training programme was based on self report, which can be seen as a limitation. Another limitation is that the trainees of the pilot programme were all neurologists and residents in neurology. Therefore it is questionable whether the results can be generalized to other medical specialisms.

\subsection{Conclusion}

Medical specialists value this evidence-based training programme as highly relevant in their consultations with MUPS patients and are willing to participate in this 14-h consultation skills training programme focused on MUPS patients based on experiential learning, modelling, role-play, feedback and techniques from Cognitive Behavioural Therapy. Further research on the effectiveness and efficiency of consultation skills training programmes for medical specialists focused on MUPS patients aimed at improving medical specialist care for MUPS patients is recommended. We welcome international evaluation of and collaboration on postgraduate MUPS focused education programmes for medical specialists and residents.

\subsection{Practice implications}

If the randomized controlled trial demonstrates effectiveness and efficiency of the MUPS focused communication skills training programme for medical specialists the intervention could be embedded in post-graduate education of medical specialists and residents. 
Weiland, A., Blankenstein, A.H., Willems, M.H.A., Saase, J.L.C.M. van, Molen, H.T. van der, Dulmen, A.M. van, Arends, L.R. Post-graduate education for medical specialists focused on patients with medically unexplained physical symptoms: development of a communicaticeskills training programme. Patient Education and Counseling: 2013, 92(3), 355-360

\section{CONFLICTS OF INTEREST STATEMENT}

The authors indicated no potential conflict of interest

\section{FUNDING AND ROLE OF SPONSOR}

This study was funded by ZonMw, the Netherlands Organization for Health Research and Development. The funding body did not influence any part of the scientific process.

\section{ACKNOWLEDGEMENTS}

We are indebted to the Dutch College of General Practitioners, who provided the original MUPS-focused communication training programme for GPs and gave permission to the use of their material. We thank Geurt Essers teacher of the pilot programme, and Eveline Floor, Hans Faddegon, Joop Dopper and Annemarie Wijnhoud, teachers of the training courses for medical specialists in six different hospitals in The Netherlands. We also thank Quartz Helmond for the use of their manual for GPs on MUPS-focused communication skills. And last but not least we thank the Department of Neurology of the Erasmus MC, University Medical Centre, Rotterdam, for enabling the facilities and staff and residents for the pilot training programme.

\section{REFERENCES}

[1] A.A. Khan, A. Khan, J. Harezlak, W. Tu, K. Kroenke Somatic symptoms in primary care: etiology and outcome Psychosomatics, 44 (2003), pp. 471-478

[2] C. Nimnuan, S. Rabe-Hesketh, S. Wessely, M. Hotopf How many functional somatic syndromes J Psychosom Res, 51 (2001), pp. 549-557

[3] T.C. olde Hartman, M.S. Borghuis, P.L. Lucassen, F.A. van de Laar, A.E. Speckens, C. van Weel Medically unexplained symptoms, somatisation disorder and hypochondriasis: course and prognosis. A systematic review J Psychosom Res, 66 (2009), pp. 363-377

[4] M.W.M. de Waal, I.A. Arnold, J.A.H. Eekhof, A.M. van Hemert Somatoform disorders in general practice: prevalence, functional impairment and comorbidity with anxiety and depressive disorders Br J Psychiatry, 184 (2004), pp. 470-476

[5] P.F.M. Verhaak, S.A. Meijer, A.P. Visser, G. Wolters Persistent presentation of medically unexplained symptoms in general practice Fam Pract, 23 (2006), pp. 414-420

[6] P. Salmon Conflict, collusion or collaboration in consultations about medically unexplained symptoms: the need for a curriculum of medical explanation Patient Educ Couns, 67 (2007), pp. 246-254

[7] J. Stone, W. Wojcik, D. Durrance, A. Carson, S. Lewis, L. MacKenzie et al. What should we say to patients with symptoms unexplained by disease? The number needed to offend Brit Med J, 325 (2002), pp. 1449-1450

[8] J.M. Bensing, P.F. Verhaak Somatisation: a joint responsibility of doctor and patient Lancet, 367 (2006), pp. 452-454 
Weiland, A., Blankenstein, A.H., Willems, M.H.A., Saase, J.L.C.M. van, Molen, H.T. van der, Dulmen, A.M. van, Arends, L.R. Post-graduate education for medical specialists focused on patients with medically unexplained physical symptoms: development of a communicationskills training programme. Patient Education and Counseling: 2013, 92(3), 355-360

[9] S. Peters, I. Stanley, M. Rose, P. Salmon Patients with medically unexplained symptoms: sources of patients' authority and implications for demands on medical care Soc Sci Med, 46 (1998), pp. 559-565

[10] S. Zavestoski, P. Brown, S. McCormick, B. Mayer, M. D'Ottavi, J.C. Lucove Patient activism and the struggle for diagnosis: Gulf War illnesses and other medically unexplained physical symptoms in the US Soc Sci Med, 58 (2004), pp. 161-175

[11] P. Salmon, S. Peters, I. Stanley Patients' perceptions of medical explanations for somatisation disorders: qualitative analysis Br Med J, 318 (1999), pp. 372-376

[12] C.F. Dowrick, A. Ring, G.M. Humphris, P. Salmon Normalisation of unexplained symptoms by general practitioners: a functional typology Br J Gen Pract, 54 (2004), pp. 165-170

[13] S. Cocksedge, C. May The listening loop: a model of choice about cues within primary care consultations Med Educ, 39 (2005), pp. 999-991005

[14] Blankenstein AH, van der Horst HE, Essers G, Floor E. Training course policy towards MUPS patients in general practice; use of CBT for the GP; 2003.

[15] A.J. Carson, B. Ringbauer, J. Stone, L. McKenzie, C. Warlow, M. Sharpe Do medically unexplained symptoms matter? A prospective cohort study of 300 new referrals to neurology outpatient clinics J Neurol Neurosurg Psychiatry, 68 (2000), pp. 207-210

[16] J. Hamilton, R. Campos, F. Creed Anxiety, depression and management of medically unexplained symptoms in medical clinics J R Coll Physicians Lond, 30 (1996), pp. 18-20

[17] K. Kroenke, A.D. Mangelsdorff Common symptoms in ambulatory care: incidence, evaluation, therapy, and outcome Am J Med, 86 (1989), pp. 262-266

[18] D.T. Stephenson, J.R. Price Medically unexplained physical symptoms in emergency medicine Emerg Med J, 23 (2006), pp. 595-600

[19] R.A. Mayou, C.M. Bass, B.M. Bryant Management of non-cardiac chest pain: from research to clinical practice Heart, 81 (1999), pp. 387-392

[20] I.G. McDonald, J. Daly, V.M. Jelinek, F. Panetta, J.M. Gutman Opening Pandora's box: the unpredictability of reassurance by a normal test result Br Med J, 313 (1996), pp. 329332

[21] L. Siproudhis, M. Delvaux, S. Chaussade, F. Charles, P. Guyot, J. Weber et al. Patientdoctor relationship in the irritable bowel syndrome. Results of a French prospective study on the influence of the functional origin of the complaints Gastroenterol Clin Biol, 26 (2002), pp. 1125-1133

[22] L.K. Bartholomew, G.S. Parcel, G. Kok Intervention mapping: a process for developing theory- and evidence-based health education programs Health Educ Behav, 25 (1998), pp. 545-563

[23] A. Weiland, R. Van de Kraats, A.H. Blankenstein, J.L.C.M. Van Saase, H.T. Van der Molen, W.M. Bramer et al. Encounters between medical specialists and patients with medically unexplained physical symptoms; influences of communication on patient outcomes and use of health care. A literature overview Perspect Med Educ, 1 (2012), pp. 192-206

[24] A.M. Van Dulmen, J.F. Fennis, H.G. Mokkink, H.G. Van der Velden, G. Bleijenberg Doctor-dependent changes in complaint-related cognitions and anxiety during medical consultations in functional abdominal complaints Psychol Med, 25 (1995), pp. 1011-1018

[25] L. Hall-Patch, R. Brown, A. House, S. Howlett, S. Kemp, G. Lawton et al. Acceptability and effectiveness of a strategy for the communication of the diagnosis of psychogenic nonepileptic seizures Epilepsia, 51 (2010), pp. 70-78 
Weiland, A., Blankenstein, A.H., Willems, M.H.A., Saase, J.L.C.M. van, Molen, H.T. van der, Dulmen, A.M. van, Arends, L.R. Post-graduate education for medical specialists focused on patients with medically unexplained physical symptoms: development of a communicationskills training programme. Patient Education and Counseling: 2013, 92(3), 355-360

[26] C. Bieber, K.G. Muller, K. Blumenstiel, A. Schneider, A. Richter, S. Wilke et al. Longterm effects of a shared decision-making intervention on physician-patient interaction and outcome in fibromyalgia. A qualitative and quantitative 1 year follow-up of a randomized controlled trial Patient Educ Couns, 63 (2006), pp. 357-366

[27] C. Bieber, K.G. Muller, K. Blumenstiel, A. Hochlehnert, S. Wilke, M. Hartmann et al. A shared decision-making communication training program for physicians treating fibromyalgia patients: effects of a randomized controlled trial J Psychosom Res, 64 (2008), pp. $13-20$

[28] R.W. Stones, W.T. Lawrence, S.A. Selfe Lasting impressions: influence of the initial hospital consultation for chronic pelvic pain on dimensions of patient satisfaction at followup J Psychosom Res, 60 (2006), pp. 163-167

[29] J. Collins, E. Farrall, D.A. Turnbull, D.J. Hetzel, G. Holtmann, J.M. Andrews Do we know what patients want? The doctor-patient communication gap in functional gastrointestinal disorders Clin Gastroenterol Hepatol, 7 (2009), pp. 1252-1254

[30] D.M. Owens, D.K. Nelson, N.J. Talley The irritable bowel syndrome: long-term prognosis and the physician-patient interaction Ann Intern Med, 122 (1995), pp. 107-112

[31] Kolb D. Experiential learning as the science of learning and development; 1984.

[32] C. Bass, S. Benjamin The management of chronic somatization The British Journal of Psychiatry, 162 (1993), pp. 472-480

[33] Care NSCGDitMH Dutch multidisciplinary guideline on MUPS and somatoform disorders Trimbos Instituut (2010)

[34] Goldstein psychological skill training: the structured learning technique Pergamon Press Inc. (1981)

[35] Lang G, van der Molen HT. Methodology of communication skills training; 1992.

[36] S.E.C. Morley, A. Williams Systematic review and meta-analysis of randomized controlled trials of cognitive behaviour therapy and behaviour therapy for chronic pain in adults, excluding headache Pain (1999), pp. 1-13

[37] M.A. Hommes Self-instruction in Communication Skills Training for Distance Education Effects on skills, self-efficacy, motivation and transfer Erasmus University Rotterdam, Rotterdam, The Netherlands (2006) Thesis, http://hdl.handle.net/1765/7685

[38] M. Berkhof, H.J. van Rijssen, A.J.M. Schellart, J.R. Anema, A.J. van der Beek Effective training strategies for teaching communication skills to physicians: an overview of systematic reviews Patient Educ Couns, 84 (2011), pp. 152-162

[39] Fossli Jensen B., Gulbrandsen P., Dahl F.A., Krupat E., Frankel R.M., A. Finset Effectiveness of a short course in clinical communication skills for hospital doctors: results of a crossover randomized controlled trial (ISRCTN22153332) Patient Educ Couns, 84

(2011), pp. 163-169 
Weiland, A., Blankenstein, A.H., Willems, M.H.A., Saase, J.L.C.M. van, Molen, H.T. van der, Dulmen, A.M. van, Arends, L.R. Post-graduate education for medical specialists focused on patients with medically unexplained physical symptoms: development of a communicationskills training programme. Patient Education and Counseling: 2013, 92(3), 355-360

TABLES AND FIGURES

Fig. 1. Model of intervention mapping.

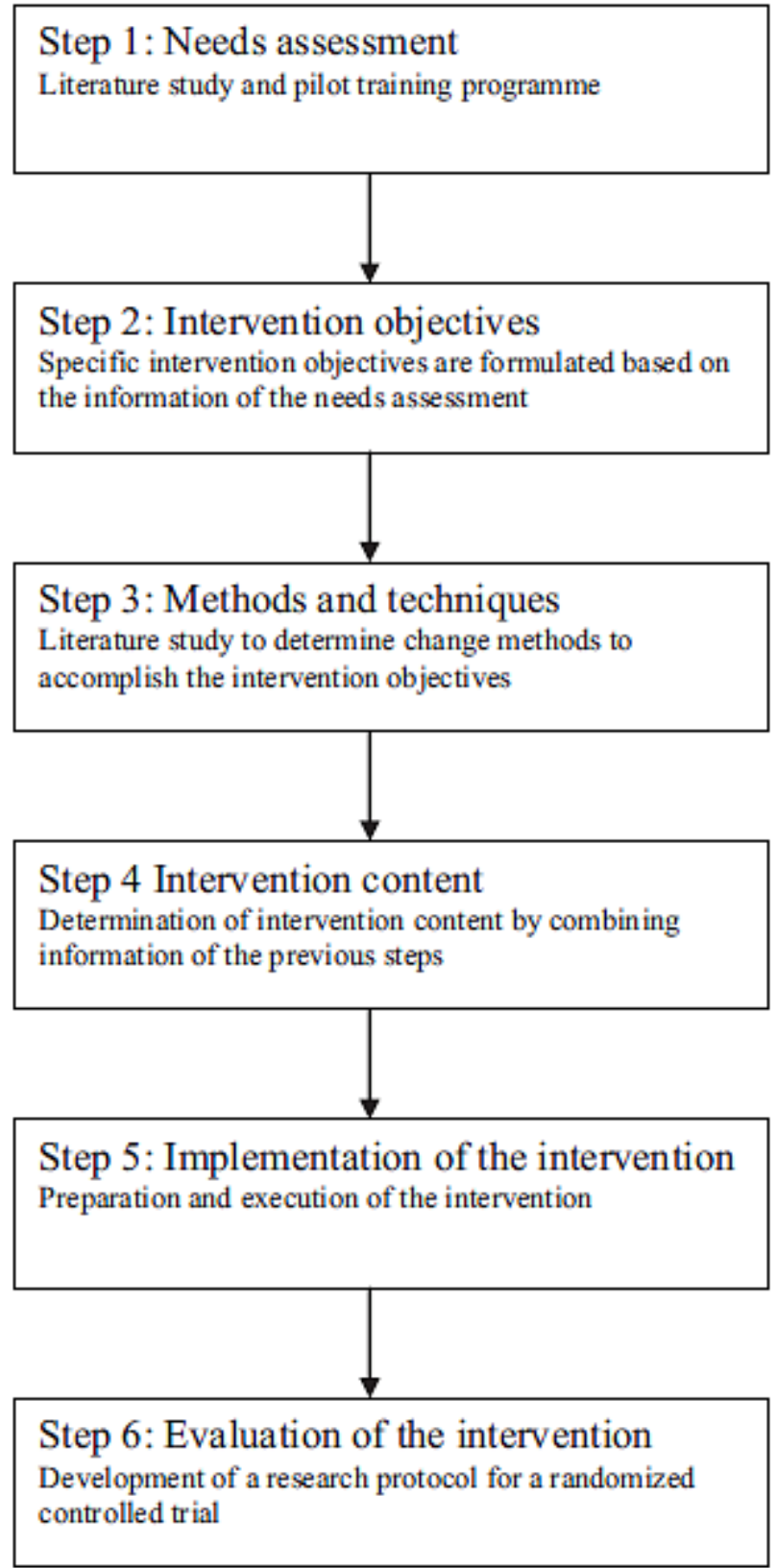


Table 1

Evaluation of pilot training programme ( $N=22 ; 3$ participants did not fill out the form).

\begin{tabular}{|c|c|c|c|}
\hline Content of the course & Not useful & Rather useful & Very useful \\
\hline Literature & 0 & 7 & 11 \\
\hline \multicolumn{4}{|l|}{ Practicing skills } \\
\hline SCEBS symptom exploration & 0 & 1 & 18 \\
\hline SCEBS informing & 0 & 5 & 14 \\
\hline SCEBS planning & 1 & 11 & 7 \\
\hline instruction symptom diary & 1 & 8 & 7 \\
\hline discussing symptom diary with patient & 1 & 7 & 11 \\
\hline reattribution & 0 & 11 & 8 \\
\hline effective reassurance & 0 & 3 & 16 \\
\hline negotiating a final test & 0 & 1 & 14 \\
\hline challenging alarming thoughts (practised in one group) & 1 & 5 & 4 \\
\hline Discussing experiences/patient case & 0 & 3 & 15 \\
\hline \multicolumn{4}{|l|}{ Course materials } \\
\hline Literature & 0 & 6 & 13 \\
\hline Volume of the training course & Too long & Just right & Too short \\
\hline Duration of the course & 2 & 15 & 2 \\
\hline Intervals between the sessions & 2 & 16 & 1 \\
\hline Time investment for the different elements of course & 0 & 18 & 0 \\
\hline Approach by trainers & Inadequate & Mediate & Good \\
\hline Instructions & 0 & 0 & 19 \\
\hline Theoretical knowledge & 0 & 3 & 16 \\
\hline Feedback & 0 & 0 & 19 \\
\hline
\end{tabular}

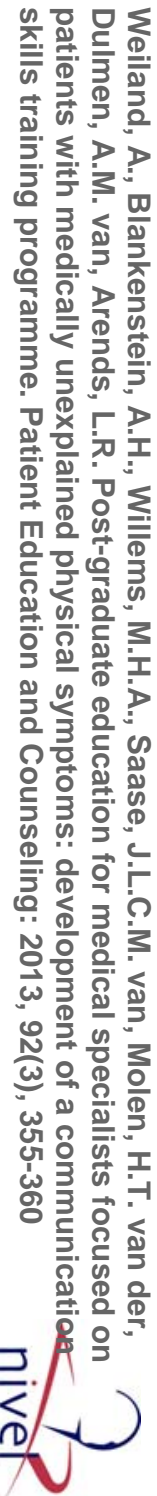


Weiland, A., Blankenstein, A.H., Willems, M.H.A., Saase, J.L.C.M. van, Molen, H.T. van der, Dulmen, A.M. van, Arends, L.R. Post-graduate education for medical specialists focused on patients with medically unexplained physical symptoms: development of a communication skills training programme. Patient Education and Counseling: 2013, 92(3), 355-360

Table 2

MUPS-focused doctor-patient communication skills.

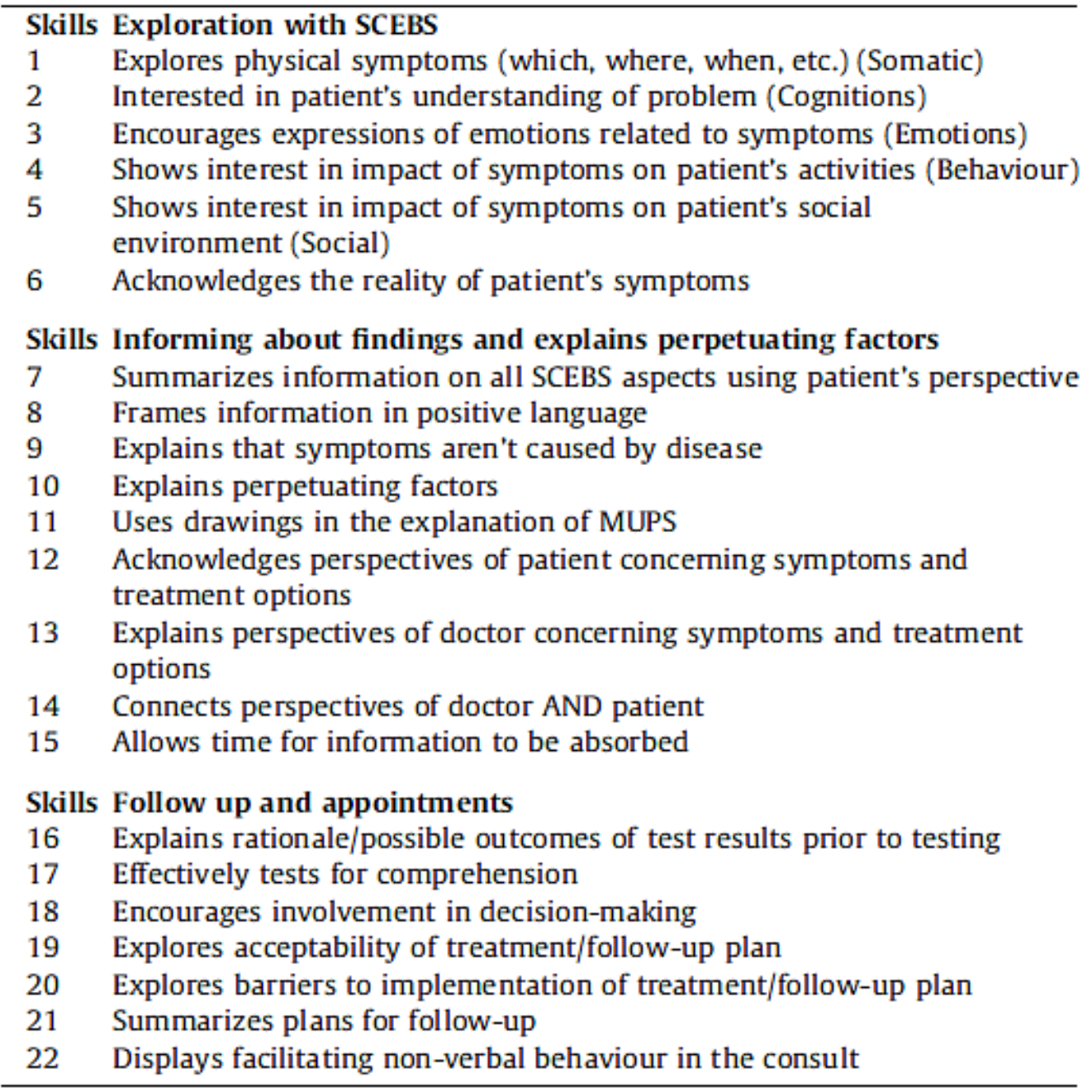


Weiland, A., Blankenstein, A.H., Willems, M.H.A., Saase, J.L.C.M. van, Molen, H.T. van der, Dulmen, A.M. van, Arends, L.R. Post-graduate education for medical specialists focused on patients with medically unexplained physical symptoms: development of a communication 7 skills training programme. Patient Education and Counseling: 2013, 92(3), 355-360

Table 3

Original GP and final specialist MUPS training programme.

\begin{tabular}{|c|c|}
\hline Original GP MUPS-focused training course & Specialist MUPS-focused training course \\
\hline $\begin{array}{l}\text { First session } \\
\text { Introduction } \\
\text { Exploring learning goals }\end{array}$ & $\begin{array}{l}\text { First session } \\
\text { Introduction } \\
\text { Exploring learning goals } \\
\text { Reflection on personal cognitions, emotions } \\
\text { and behaviour towards MUPS patients }\end{array}$ \\
\hline $\begin{array}{l}\text { Practicing skills: } \\
\text { Exploring Somatic, Cognitive, } \\
\text { Emotional, Behaviour and Social } \\
\text { Aspects of the complaints (SCEBS) } \\
\text { Informing patients about MUPS } \\
\text { Planning } \\
\text { Discussion and homework }\end{array}$ & $\begin{array}{l}\text { Practicing skills: } \\
\text { Exploring Somatic, Cognitive, } \\
\text { Emotional, Behaviour and Social } \\
\text { Aspects of the complaints (SCEBS) } \\
\text { Informing patients about MUPS } \\
\text { Drawing vicious circle of maintaining factors for MUPS } \\
\text { Discussion and homework }\end{array}$ \\
\hline $\begin{array}{l}\text { Second session } \\
\text { Exchange of experiences } \\
\text { Practicing skills: } \\
\text { Instruction of symptom diary } \\
\text { Evaluation of symptom diary } \\
\text { Reattribution }\end{array}$ & $\begin{array}{l}\text { Second session } \\
\text { Exchange of experiences } \\
\text { Practicing skills: } \\
\text { Reassuring effectively } \\
\text { Management of expectations } \\
\text { Dealing with complex referrals } \\
\text { Report findings in letter to GP }\end{array}$ \\
\hline Discussion and homework & Discussion and homework \\
\hline $\begin{array}{l}\text { Third session } \\
\text { Exchange of experiences } \\
\text { Practicing skills: }\end{array}$ & $\begin{array}{l}\text { Third session } \\
\text { Exchange and discussion of their letters to GP }\end{array}$ \\
\hline $\begin{array}{l}\text { Reassuring patients with persistent illness worry } \\
\text { Quit reassuring patients with persistent illness worry } \\
\text { Challenging alarming thoughts } \\
\text { Negotiating final test } \\
\text { Referring to mental health care }\end{array}$ & $\begin{array}{l}\text { Treatment of MUPS in Mental Health Care } \\
\text { Presentations in couples of case-material and new skills }\end{array}$ \\
\hline Discussion and homework & Discussion and homework \\
\hline Intervision with participants in small groups & Individually watching of own video-taped MUPS consultations \\
\hline $\begin{array}{l}\text { Fourth session } \\
\text { Presentation of case-material } \\
\text { Feedback on audio/video-tapes } \\
\text { Practicing what is still difficult } \\
\text { Discussion and evaluation of course }\end{array}$ & $\begin{array}{l}\text { Fourth session } \\
\text { Self-efficacy of their MUPS consultation skills } \\
\text { Practicing what is still difficult } \\
\text { SMART intention for keeping skills in shape } \\
\text { Discussion and evaluation of course }\end{array}$ \\
\hline
\end{tabular}

